\title{
The microstructural and thermal characteristics of silica nanoparticle-modified cement mortars after exposure to high temperatures. Part II
}

\author{
P. Sikora (iD) \\ West Pomeranian University of Technology, Szczecin, Poland; \\ Technische Universität Berlin, Germany
}

Corresponding author: e-mail: pawel.sikora@zut.edu.pl

\begin{abstract}
This study presents an investigation of the effects of high temperature on the thermal and microstructural properties of cement mortars modified with nanosilica. In the first stage of the research, the effects of nanosilica (NS) and silica fume (SF) on the hydration and compressive strength of cementitious composites were compared. In the second stage, four different types of cement mortars, containing an optimal dosage of NS, were produced. Two of them contained a normal weight aggregate (quartz or limestone), whilst two contained a heavy weight aggregate (barite or magnetite). Specimens without NS were produced for control purposes. The specimens were exposed to $300,450,600$ and $800^{\circ} \mathrm{C}$, with their post-heating properties - including thermal conductivity, specific heat, solvent absorption and cracking behavior - analyzed. The results show that NS exhibits significantly higher reactivity with cement than SF. NS accelerates the cement hydration process and contributes more significantly to the 28 and 365 day compressive strength of mortar, as compared to SF. The incorporation of NS in a composite substantially decreases the amount of $\mathrm{CH}$ in the mixture and leads to the production of additional $\mathrm{C}-\mathrm{S}-\mathrm{H}$ gel phase, which improves microstructure. The study also shows that NS contributes to a decrement in the thermal conductivity and density of mortar, both prior to and after heating. The incorporation of NS has a beneficial effect on decreasing the deterioration rate of mortars after heating, by decreasing absorption rate and the amount of cracks in in them.
\end{abstract}

KEYWORDS: cement mortar, nanosilica, elevated temperature, thermal properties, cracking.

ACKNOWLEDGMENTS: Supported by the Foundation for Polish Science (FNP).

FOR CITATION: Sikora P. The microstructural and thermal characteristics of silica nanoparticle-modified cement mortars after exposure to high temperatures. Part II. Nanotechnologies in Construction. 2020, Vol. 12, no. 3, pp. 147-154. DOI: 10.15828/20758545-2020-12-3-147-154.

Part I of the paper by P. Sikora «The microstructural and thermal characteristics of silica nanoparticle-modified cement mortars after exposure to high temperatures» was published in the journal «Nanotechnologies in Construction» 2020, Vol. 12, no. 2.

\section{RESULTS AND DISCUSSION}

\subsection{Thermal conductivity and the specific heat of mor- tars after heating}

Fig. 6 presents the results of thermal conductivity (TC) tests, before and after the exposure of specimens to elevated temperature. Since the water to paste ratio volume was fixed for all specimens, the thermal properties of the mor- tars were mainly related to the type of aggregate used. Directly after heating, the highest thermal conductivity was reported for mortars containing quartz aggregates, which can be attributed to the high crystallinity of quartz aggregate; the next highest thermal conductivity was found to have occurred for the magnetite aggregate. The thermal conductivities of Q0, LS0, M0 and B0 mortars were 2.16, $1.54,1.82$ and $1.05 \mathrm{~W} / \mathrm{mK}$, respectively. Despite its high density, the barite aggregate possessed a low TC, meaning

(c) P. Sikora, 2020 
that mortar B0 exhibited a thermal conductivity of 1.05 $\mathrm{W} / \mathrm{mK}$; more than twice as low as that of Q0. Incorporation of NS in the mixes resulted in the production of specimens with lower thermal conductivities, with specimens R3, LS3, M3 and B3 exhibiting values of 2.04, 1.46, 1.69 and $0.9 \mathrm{~W} / \mathrm{mK}$, respectively. This phenomenon - of the presence of NS decreasing the thermal conductivity of composites - has already been reported by a few researchers, with some authors also arguing that this is one of the factors responsible for improving the thermal resistance of NS-modified specimens [24]. While the exposure of the specimens to elevated temperatures resulted in a gradual decrement in their thermal conductivities, a slightly different trend was observed in the case of magnetite aggregate mortars. Above $300{ }^{\circ} \mathrm{C}$, a loss in thermal conductivity of between $4 \%$ to $15 \%$ was observed, with the lowest loss occurring for specimen B3 and the highest for R0. After exposure to $450{ }^{\circ} \mathrm{C}$, further losses in thermal conductivity were observed for mortars Q, LS and B, with specimens containing the magnetite aggregate exhibiting only limited losses in TC. This can be attributed to the high thermal stability of magnetite, which is composed mainly of $\mathrm{Fe}_{3} \mathrm{O}_{4}$. After exposure to $600{ }^{\circ} \mathrm{C}$, a significant drop in $\mathrm{TC}$ was reported in specimens containing the quartz aggregate. This phenomenon can be linked to the crystalline character of this aggregate and its phase transformation $[25,26]$. While a difference between the NS and pristine specimen was still visible at up to $600{ }^{\circ} \mathrm{C}$, after exposure to $800{ }^{\circ} \mathrm{C}$ the ratio between the specimens vanished almost completely. The residual thermal conductivity values of the specimens are presented in Fig. 7. According to these results, the mortars containing the normal-weight ag- gregates exhibited the highest thermal conductivity losses with increments in temperature. Furthermore, specimens lost more than $50 \%$ of their initial TC after exposure to $800{ }^{\circ} \mathrm{C}$. A significantly lower loss was found to have occurred for specimens containing heavy-weight aggregates.

The results of specific heat tests are presented in Fig. 8. Specific heat is highly susceptible to changes resulting from the physical and chemical processes occurring in aggregates or cement pastes, such as vaporization of free water at about $100{ }^{\circ} \mathrm{C}$ or the dissociation of $\mathrm{CH}$ at between $400{ }^{\circ} \mathrm{C}$ and $500{ }^{\circ} \mathrm{C}$ [25]. In general, mortars containing quartz, limestone or barite aggregates exhibited relatively comparable initial specific heats, ranging between 1.62 and $1.82 \mathrm{MJ} / \mathrm{m}^{3} \mathrm{~K}$, while magnetite aggregate mortars exhibited substantially higher values. Exposure to $300{ }^{\circ} \mathrm{C}$ did not result in significant changes in the specific heat values of specimens Q, LS or B, but an increment was observed for the $\mathrm{M}$ specimens, up to a temperature of $600{ }^{\circ} \mathrm{C}$. This phenomenon is attributable to the phase transition of magnetite to hematite [27], which occurs during the heating process. In the cases of the other specimens, exposure to $450{ }^{\circ} \mathrm{C}$ resulted in a noticeable increment in the specific heats of the LS specimens, while a noticeable reduction occurred for the B specimens. Only a slight increment was observed in the case of the Q specimens. According to the literature, carbonate aggregates such as limestone or dolomite have higher specific heats at higher temperature ranges, because of an endothermic reaction which results from the decomposition of the aggregate. Accordingly, spalling is minimized and the fire resistance of structural components is enhanced [28]. The specific heat increment is highly dependent on the exact chemical

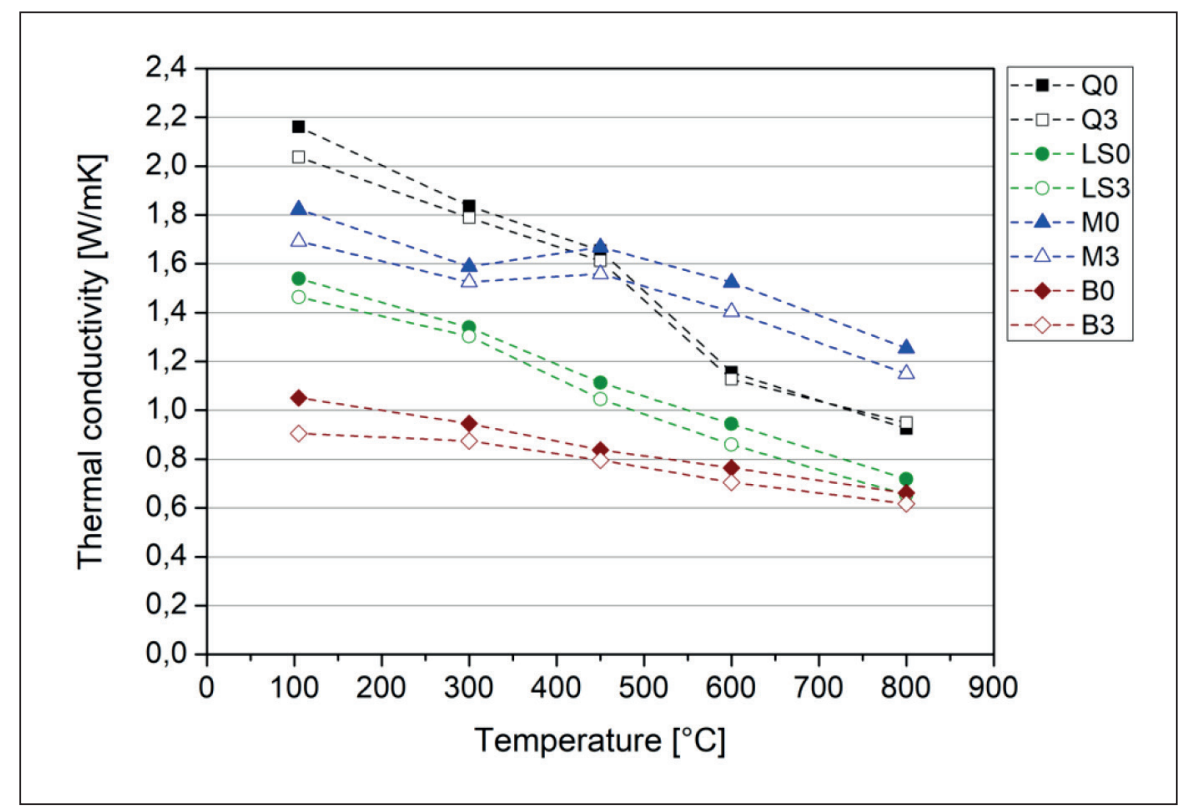

Fig. 6. Thermal conductivity of cement mortars as a function of temperature 


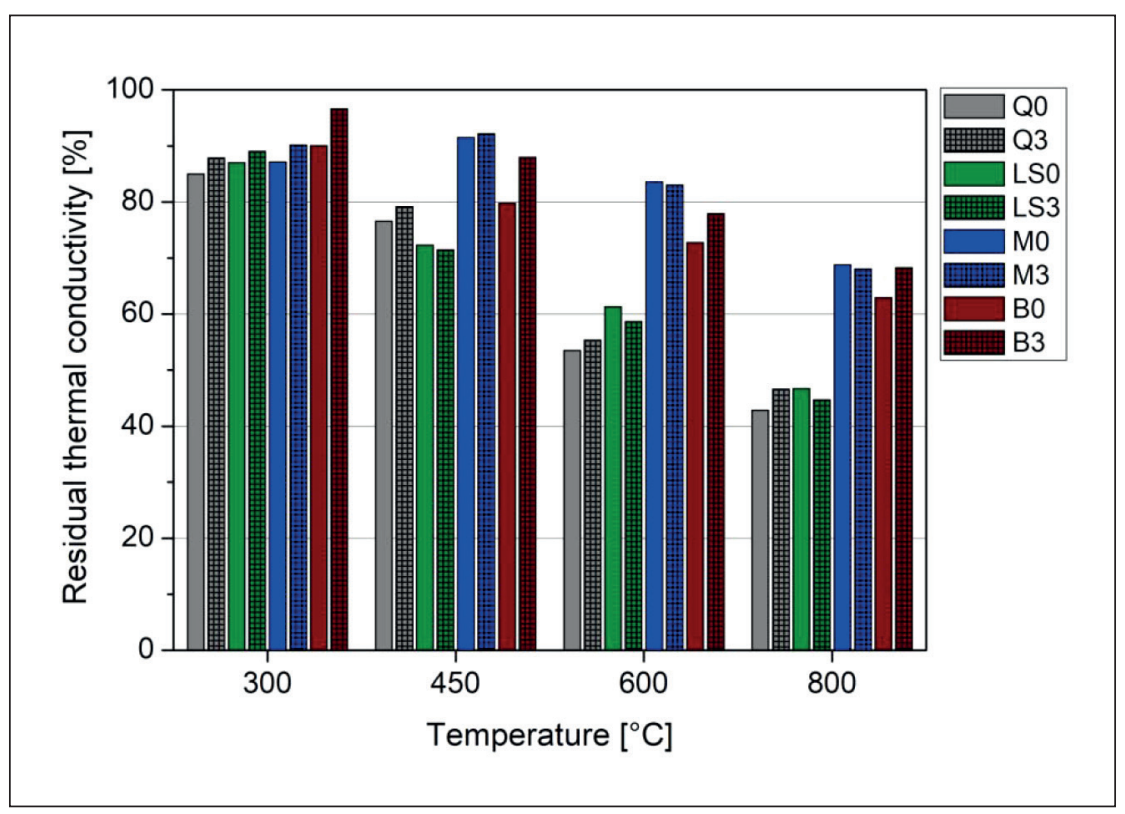

Fig. 7. Residual thermal conductivity of mortars after heating

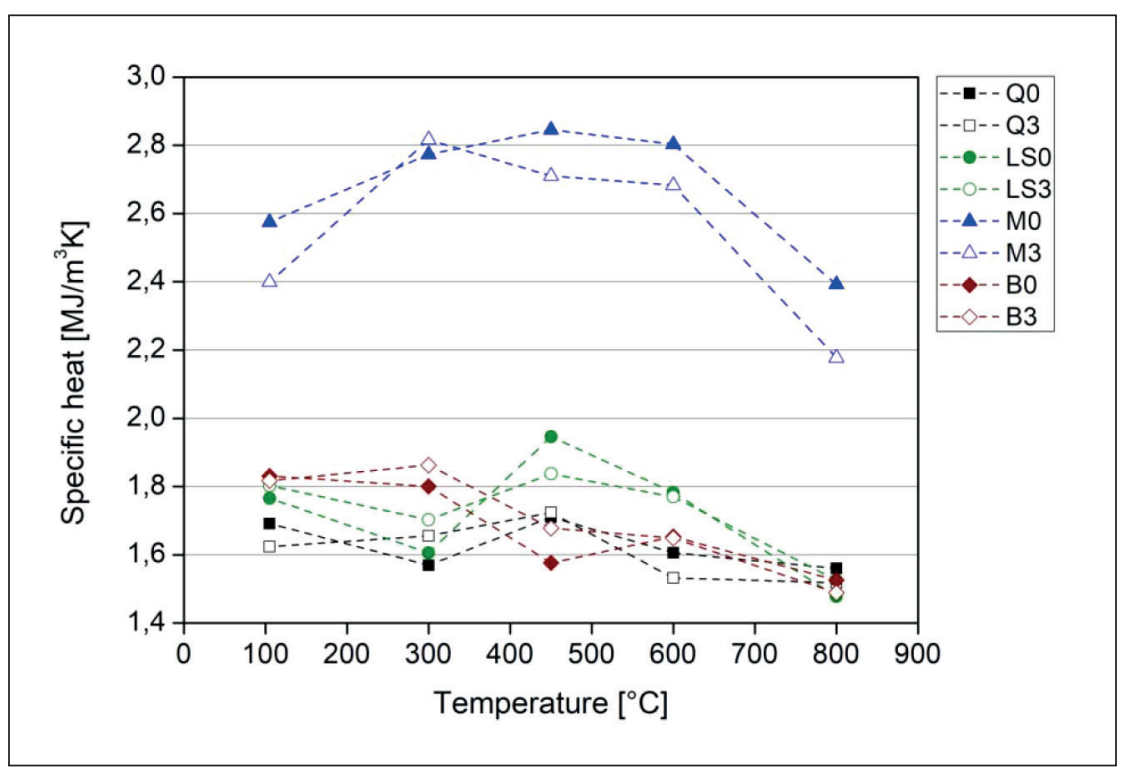

Fig. 8. Specific heat of cement mortars as a function of temperature

composition of the carbonate aggregates and it can occur from 400 to $800^{\circ} \mathrm{C}$, depending on the aggregate $[2,25]$. This study has confirmed that LS specimens exhibit higher specific heat values between 450 to $600^{\circ} \mathrm{C}$. In the case of the quartz aggregate, only a slight, indistinct increment in specific heat was seen, which is in line with other studies [25]. After exposure to $800{ }^{\circ} \mathrm{C}$, the specimens exhibited a noticeable drop in specific heat, with specimens Q, LS and $\mathrm{B}$ exhibiting comparable values. Based on the results, it is difficult to draw any meaningful conclusions regarding the relationship between the effects of NS and the specific heat of mortars

\subsection{Density after heating}

The results of density evolution tests, as a function of heating temperature, are depicted in Fig. 9. The initial oven-dry density of mortars Q0 and LS0 were $2.11 \mathrm{~g} / \mathrm{cm}^{3}$ and $2.18 \mathrm{~g} / \mathrm{cm}^{3}$, respectively. NS-modified specimens Q3 and LS3 exhibited oven-dry densities of $2.07 \mathrm{~g} / \mathrm{cm}^{3}$ and $2.12 \mathrm{~g} / \mathrm{cm}^{3}$, respectively. As expected, the density of the mortars containing heavyweight aggregates was significantly higher than those of the mortars containing norma-lweight aggregates, as a result of the high density of the aggregates themselves; they were $3.03 \mathrm{~g} / \mathrm{cm}^{3}$, 


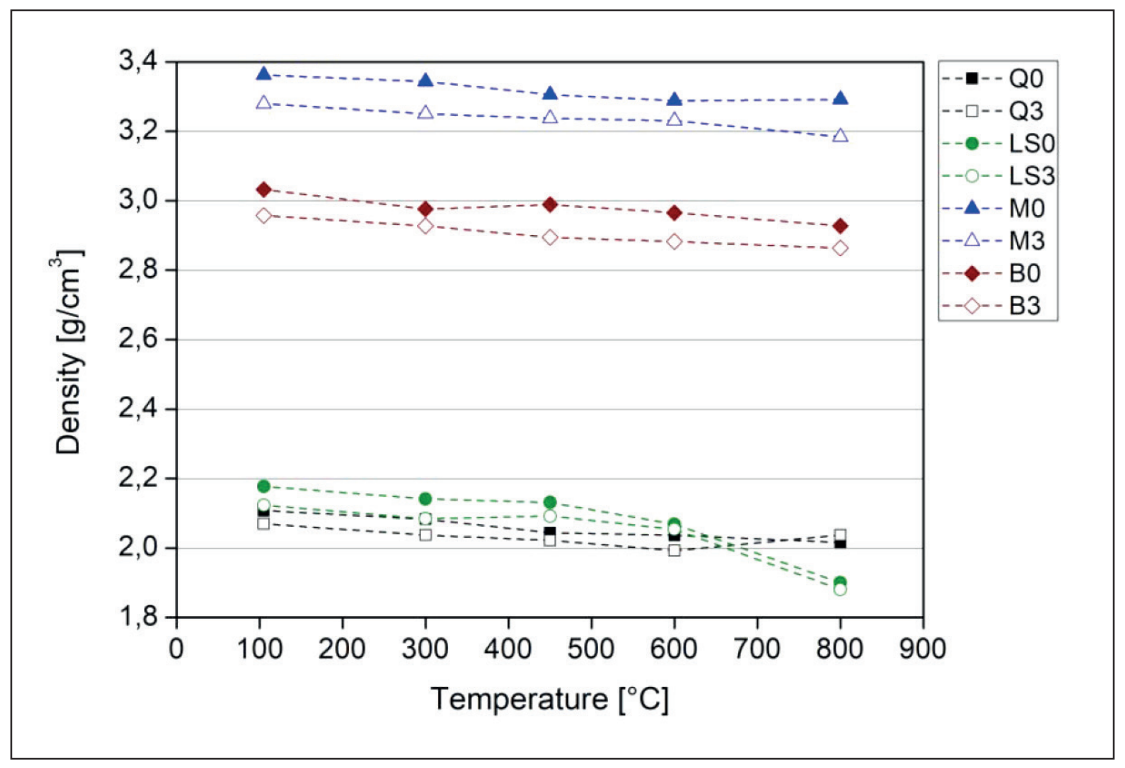

Fig. 9. Density of mortars as a function of temperature

$2.96 \mathrm{~g} / \mathrm{cm}^{3}, 3.36 \mathrm{~g} / \mathrm{cm}^{3}$ and $3.28 \mathrm{~g} / \mathrm{cm}^{3}$ for specimens B0, B3, M0, M3, respectively. NS clearly contributed to a slight decrement in the density of specimens, when added to the mixture. This effect can be attributed to the lower specific gravity of NS, as compared to cement. A similar effect can be observed when SF is incorporated in cementitious-composites, but it is more pronounced as higher dosages of SF are usually used [29]. Exposure to temperature resulted in a gradual decrement in the densities of specimens, as a result of the evaporation of water and the decomposition of the components of the cement matrix. Moreover, density decreased as result of the increase in cracks in the specimens. At up to $800{ }^{\circ} \mathrm{C}$, the density of specimens in mortars containing quartz, barite or magnetite aggregates decreased by up to $5 \%$ of the starting density. In distinction to this, a significant density decrement of over $10 \%$ was observed in the mortars containing limestone, as a result of the decomposition of this aggregate at such a temperature.

In general, the literature reports that the mass loss in both carbonate and siliceous aggregates, at up to about $600{ }^{\circ} \mathrm{C}$, is minimal. Furthermore, the dissociation of ordinary limestone can start at temperatures as low as about $400{ }^{\circ} \mathrm{C}$ [1]. However, beyond $600{ }^{\circ} \mathrm{C}$ aggregate decomposition occurs at a rate loss of $44 \mathrm{wt} \%$, corresponding to the stoichiometric $\mathrm{CO}_{2}$ amount in $\mathrm{CaCO}_{3}$, thus making significant mass loss a possibility $[1,25$, 30]. In the case of heavy-weight aggregates, a gradual decrement in the density of the specimens was found. It was very low in the case of magnetite, due to the superior thermal stability of this aggregates at elevated temperatures. However, the barite specimens exhibited severe aggregate spalling on their surfaces, thus indicating an increase in mass loss.

\subsection{Solvent absorption after heating}

Fig. 10 presents the results of acetone absorption by the mortar specimens, after heating. It was found that while acetone has slightly different effects on pore filling than water, the method can nevertheless be successfully applied to provide indirect information on the pore structure deterioration rate, after heating. After exposure to $300{ }^{\circ} \mathrm{C}$, pristine and NS-modified specimens exhibited relatively comparable absorption values, though slightly higher absorption rates were seen for specimens LS3, M3 and B3. This might have been caused by the higher volume of $\mathrm{C}-\mathrm{S}-\mathrm{H}$ gel decomposition in the NS-specimens (Section 4.2). A further rise in temperature resulted in a gradual increment in the porosity of specimens. After exposure to $450{ }^{\circ} \mathrm{C}$, the specimens containing quartz, limestone or barite aggregate exhibited noticeable porosity increments, while mortars containing the magnetite aggregate exhibited only a slight increment. In all cases, the NS-modified specimens exhibited lower acetone absorption than their corresponding pristine specimens. A substantial increment in acetone absorption occurred after exposure to $600{ }^{\circ} \mathrm{C}$. This temperature is known to be detrimental to OPC composites, due to the ongoing decomposition of hydration products, as well as because of the development of thermal incompatibility between the cement paste and the aggregates. A drastic increment in absorption was reported for mortars containing quartz aggregate, followed by those with the limestone aggregate. However, as discussed above, the change in the mass of 


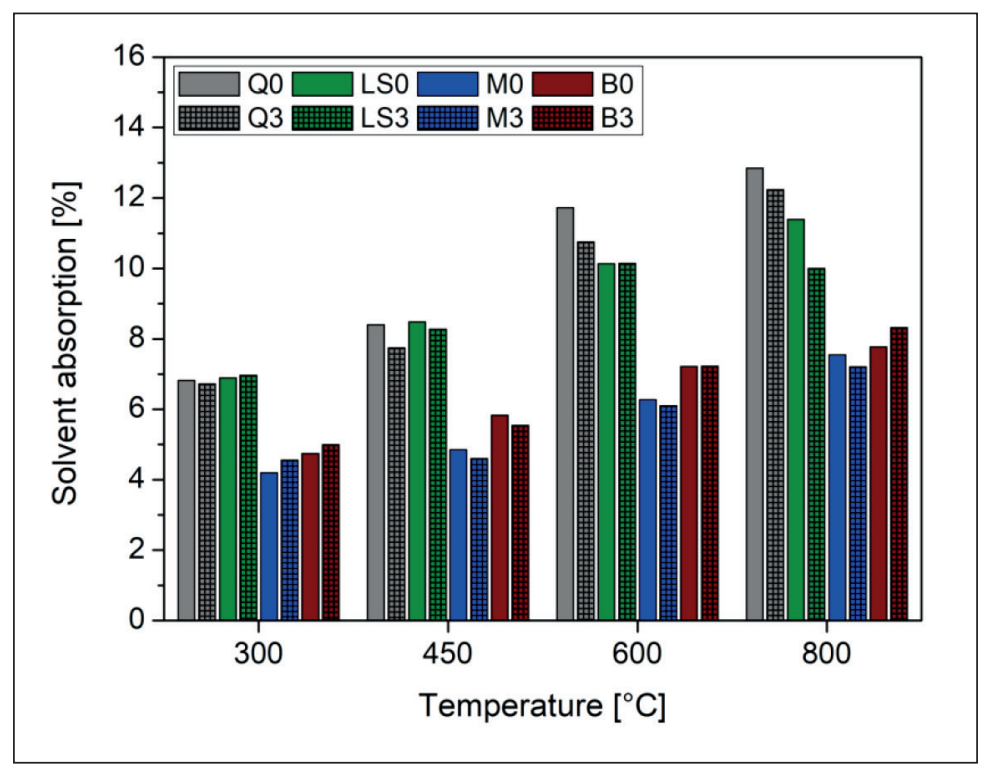

Fig. 10. Acetone absorption of mortars after heating

the aggregates themselves was relatively limited, as the effects of high temperature on quartz aggregate mortars are completely different from those on carbonate aggregate mortars. At a temperature of $600{ }^{\circ} \mathrm{C}$ the strain value of quartz aggregate can be up to twice as high as that of carbonate aggregates $[1,26,28,30]$. This results in microcracking, which in turn increases matrix porosity, thereby confirming that carbonaceous aggregates are more resistant to temperature in the medium heating range and that highly crystalline quartz aggregate suffers from serious cracking as a result of its expansion. Surprisingly, after exposure to $800{ }^{\circ} \mathrm{C}$ and despite significant mass loss (as reported above) mortars containing quartz aggregate still exhibited higher absorption rates. This might be explained by the fact that quartz specimens underwent much higher micro-cracking than LS-mortars, as a result of thermal expansion. In the case of mortars containing heavy-weight aggregates, a gradual increment in acetone absorption was observed, with the barite aggregate specimens exhibiting higher absorption than the magnetite specimens, with increasing temperature. In addition, when the $\mathrm{B} 3$ mortar was exposed to $800^{\circ} \mathrm{C}$, a higher acetone absorption was seen. This phenomenon has been previously reported in study [31], showing that barite aggregates exhibit high water absorption, thus leaving less water available for the cement paste. In the presence of NS, the cement mortar matrix becomes more compacted; together with the high susceptibility of barite aggregates to cracking, this resulted in increased micro-cracking in the specimen. In general, it can concluded that NS-modified specimens exhibited lower absorption rates than the corresponding pristine mortars, which confirms the MIP findings regarding decrements in composite porosity.

\subsection{Visual inspection after 14 days}

14 days after exposure to elevated temperature, specimens were inspected visually to assess their deterioration rates. After heating, they were placed in ambient conditions so as to facilitate free contact with atmospheric moisture. As has been reported by many researchers, specimens undergo deterioration when exposed to moisture as a result of rehydration, which leads to cracking and thus a decrease in their mechanical performance with time $[3,32,33]$. No alteration was observed on the surface of mortar specimens at up to $300{ }^{\circ} \mathrm{C}$, which is why no data regarding those instances has been included here. However, narrow and short cracks were found in specimens containing quartz aggregate, after exposure to $450{ }^{\circ} \mathrm{C}$ (Fig. 11). The surfaces of mortars containing the barite aggregate were damaged as a result of its thermally induced spalling. This type of aggregate exhibits anisotropic properties, with its thermal expansion varying in different directions; it thus has a tendency to crack with increments in temperature [31]. It is therefore not an appropriate aggregate for use in composites exposed to elevated temperatures.

The surfaces of specimens exposed to temperatures of $600{ }^{\circ} \mathrm{C}$ and $800{ }^{\circ} \mathrm{C}$ are presented in Figures 12 and 13, respectively. Noticeable cracking of specimens containing quartz, barite and magnetite aggregates is visible after exposure to $600^{\circ} \mathrm{C}$. No deterioration on the surface of the LS mortars is visible, which can be attributed to their low thermal expansion and the satisfactory resistance of the aggregate to temperatures up to $600{ }^{\circ} \mathrm{C}$ [25]. Surprisingly, despite the good thermal stability of magnetite, a crack also occurred on the surface of the magnetite mortar, M0, 


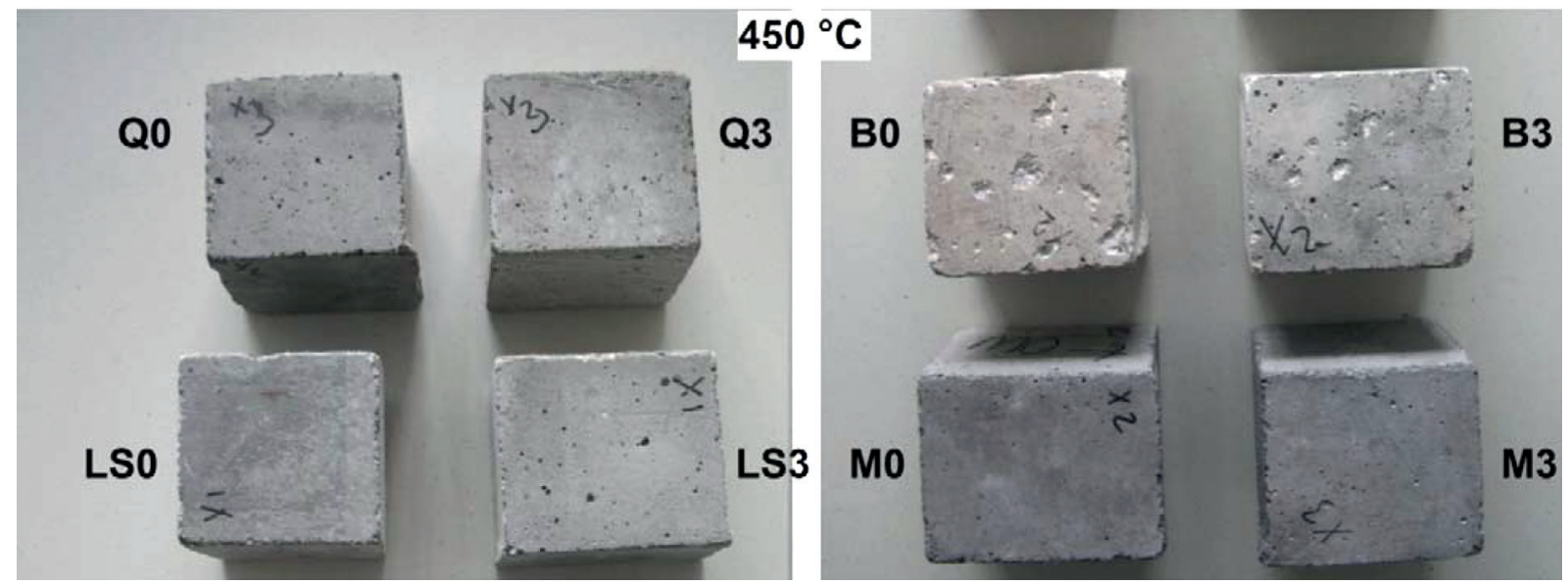

Fig. 11. Visual inspection of the specimens after exposure to $450{ }^{\circ} \mathrm{C}$
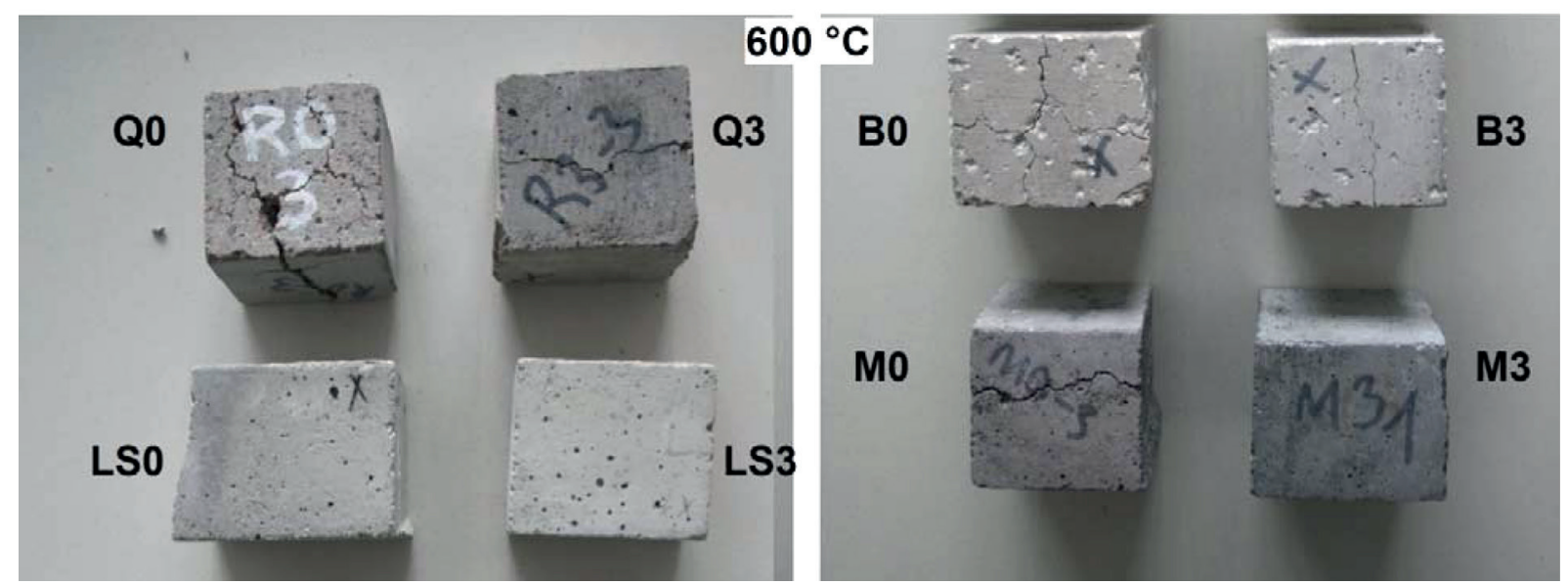

Fig. 12. Visual inspection of the specimens after exposure to $600{ }^{\circ} \mathrm{C}$

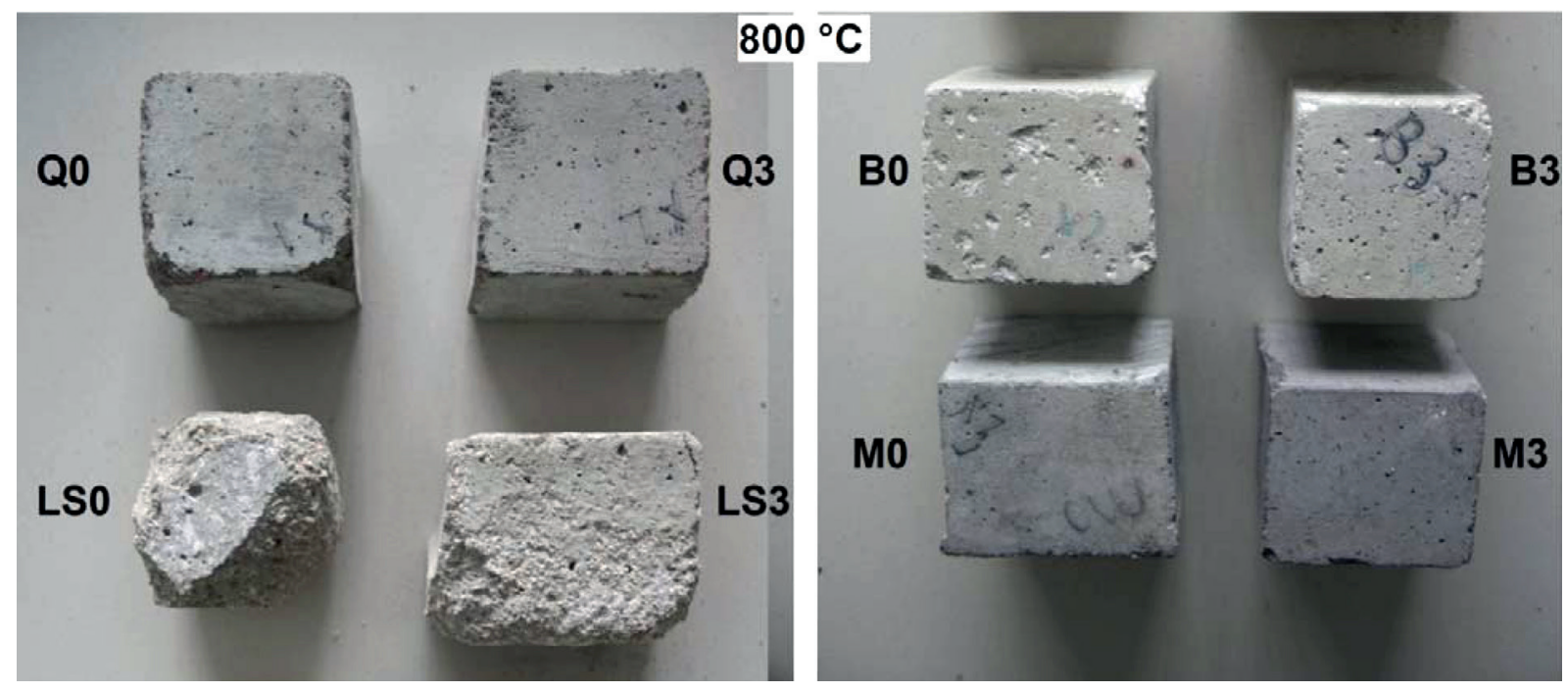

Fig. 13. Visual inspection of the specimens after exposure to $800{ }^{\circ} \mathrm{C}$ 
after 14 days of exposure. The addition of NS resulted in less surface cracking, with none observed for M3 and only limited cracking in R3 and B3, as compared to R0 and $\mathrm{B} 0$. After exposure to $800{ }^{\circ} \mathrm{C}$, damage or the falling of the edges of the Q0 mortars was visible, as well as severe disintegration of the mortars produced with the limestone aggregate. This is attributable to decomposition of the limestone aggregate, followed by rehydration of the $\mathrm{CaO}$ formed, which is accompanied by significant expansion. Furthermore, at this heating temperature, specimens containing NS exhibited lower deterioration rates than pristine mortars. Surprisingly, after 14 days, specimens exposed to $600{ }^{\circ} \mathrm{C}$ exhibited higher cracking rates than specimens exposed to $800{ }^{\circ} \mathrm{C}$. This can be attributed to the fact that, at a temperature of $600{ }^{\circ} \mathrm{C}$, not all of the hydration products undergo total decomposition, so that specimens' rehydration processes occur more actively during their contact with moisture (i.e. rehydration of $\mathrm{CH}$ results in significant cracking). A similar phenomenon, whereby higher surface cracking occurs at lower temperature, has been reported in another study [28]. Overall, it was observed that specimens containing NS decreased the cracking rate, or even protected specimens from cracking, after 14 days of exposure to atmospheric moisture. It has been widely reported that $\mathrm{CH}$ has a significant effect on the cracking potential of mortars and therefore that specimens with lower $\mathrm{CH}$ contents are more resistant to cracking. The TGA study performed on 28 day old specimens confirmed this phenomenon (see Section 4.2, above). In addition, nanosilica refines microstructure, producing higher amounts of the $\mathrm{C}-\mathrm{S}-\mathrm{H}$ phase and increasing the bonding between cement paste and aggregate, thus resulting in increased resistance to elevated temperatures.

\section{CONCLUSIONS}

The following conclusions can be drawn from the present work:

- Nanosilica exhibits higher reactivity with cement than does silica fume. Moreover, in comparison to silica fume, NS accelerates the cement hydration process and contributes more significantly to the 28 and 365 day compressive strength of mortars.

- NS has a substantial effect on decreasing the amount of $\mathrm{CH}$ in a mixture and increasing the production of $\mathrm{C}-\mathrm{S}-\mathrm{H}$ gel phase. The incorporation of NS leads to the production of a more compacted and refined microstructure, thus improving mortars' transport and mechanical properties.

- The incorporation of NS results in a decrement in the density of mortars, as well as a reduction in their thermal conductivity, prior to and after exposure to elevated temperatures. No direct correlation between NS and specific heat was established.

- After exposure to elevated temperatures, NS-modified mortars exhibit lower absorption s than mortars without NS. This effect is attributable to NS mortars' more refined microstructures as well as to decreased cracking.

- Due to a decreased amount of $\mathrm{CH}$ in NS-modified mortars, they exhibit lower deterioration rates after exposure to elevated temperature; NS is thus beneficial in improving the heat resistance of cementitious composites.

\section{REFERENCES}

24. Kumar R., Singh S., Singh L.P. Studies on enhanced thermally stable high strength concrete incorporating silica nanoparticles. Construction and Building Materials. 2017, vol. 153, pp. 506-513. DOI: 10.1016/j.conbuildmat.2017.07.057.

25. Naus D.J. A compilation of elevated temperature concrete material property data and information for use in assessments of nuclear power plant reinforced concrete structures. (NUREG/CR-7031). United States Nuclear Regulatory Commission, 2010.

26. Xing Z., Beaucour A-L., Hebert R., Noumowé A., Ledésert B. Influence of the nature of aggregates on the behaviour of concrete subjected to elevated temperature. Cement and Concrete Research. 2011, vol. 41, pp. 392-402. DOI: 10.1016/j.cemconres.2011.01.005.

27. Grosu Y., Faik A., Ortega-Fernández I., D’Aguanno B. Natural Magnetite for thermal energy storage: Excellent thermophysical properties, reversible latent heat transition and controlled thermal conductivity. Solar Energy Materials and Solar Cells. 2017, vol. 161, pp. 170-176. DOI: 10.1016/j.solmat.2016.12.006.

28. Kodur V. Properties of concrete at elevated temperatures. ISRN Civil Engineering. 2014, pp. 1-15. DOI: 10.1155/2014/468510.

29. Xu Y., Chung D.D.L. Cement of high specific heat and high thermal conductivity, obtained by using silane and silica fume as admixtures. Cement and Concrete Research. 2000, vol. 30, no. 7, pp. 1175-1178. DOI: 10.1016/S0008-8846(00)00296-9.

30. Tufail M., Shahzada K., Gencturk B., Wei J. Effect of elevated temperature on mechanical properties of limestone, quartzite and granite concrete. International Journal of Concrete Structures and Materials. 2017, vol. 11, no. 1, pp. 17-28. DOI: 10.1007/ s40069-016-0175-2. 
INTERNATIONAL EXPERIENCE

31. Horszczaruk E., Sikora P., Cendrowski K., Mijowska E. The effect of elevated temperature on the properties of cement mortars containing nanosilica and heavyweight aggregates. Construction and Building Materials. 2017, vol. 137, pp. 420-431. DOI: 10.1016/j.conbuildmat.2017.02.003.

32. Torić N., Boko I., Juradin S., Baloević G. Mechanical properties of lightweight concrete after fire exposure. Structural Concrete. 2016, vol. 17, no. 6, pp. 1071-1081. DOI: 10.1002/suco.201500145.

33. Torić N., Boko I., Peros B. Reduction of postfire properties of high-strength concrete. Advances in Materials Science and Engineering. 2013, vol. 712953. DOI: 10.1155/2013/712953.

INFORMATION ABOUT THE AUTHOR

Pawel Sikora, PhD, Assistant Professor, Department of Building Engineering, Faculty of Civil Engineering and Architecture, West Pomeranian University of Technology, Szczecin, Poland; Postdoctoral researcher at Building Materials and Construction Chemistry, Technische Universität Berlin, Berlin, Germany; ORCID: http://orcid.org/0000-0003-1092-1359; e-mail: pawel.sikora@zut.edu.pl

\section{Author declare the absence of any competing interests.}

Received: 15.03 .2020 .

Revised: 10.04.2020.

Accepted: 10.04 .2020 . 